\title{
Designing and evaluating new approaches to instruction
}

\author{
Paula Heron* \\ University of Washington \\ E-mail: pheron@uw.edu
}

\begin{abstract}
Results from research indicate that many students emerge from traditional undergraduate science courses without having developed a functional understanding of important basic concepts. These findings have motivated changes in undergraduate courses in the sciences, mathematics, and engineering. Many newer strategies are described as "interactive" in that students are expected to engage in discussions with each other, and with professors during class time. Many strategies also involve paying attention to the ideas and beliefs that students have upon entering the classroom, ideas and beliefs that have they developed during previous formal instruction, and through their everyday experience with the natural world. Evaluating the effectiveness of these strategies requires a careful assessment of the goals of instruction and attention to a number of variables, many of which cannot be controlled. Examples will be used to illustrate the process of designing and evaluating instructional approaches and materials. The context will be physics but analogies can be made to other disciplines.
\end{abstract}

Frontiers of Fundamental Physics 14 - FFP14,

15-18 July 2014

Aix Marseille University (AMU) Saint-Charles Campus, Marseille

\footnotetext{
*Speaker.
} 